\title{
The impact of new national HIV testing guidelines at a district general hospital in an area of high HIV seroprevalence
}

\author{
${ }^{1}$ I Page, ${ }^{2} \mathrm{M}$ Phillips, ${ }^{3} \mathrm{P}$ Flegg, ${ }^{4} \mathrm{R}$ Palmer \\ ${ }^{1}$ ST5 Specialty Registrar in Infectious Diseases, North Manchester General Hospital, Manchester, UK; ${ }^{2}$ Clinical Lecturer in Medical Education/ \\ Specialist Registrar in Genito-Urinary Medicine, Trinity College, Dublin, Ireland; ${ }^{3}$ nfectious Diseases Consultant; ${ }^{4}$ Medical Microbiology \\ Consultant, Blackpool Victoria Hospital, Blackpool, UK
}

\begin{abstract}
The latest UK national human immunodeficiency virus (HIV) testing guidelines, released in September 2008, state that HIV testing should be offered to all patients with indicator conditions and considered in all general medical admissions in high-prevalence areas. We audited testing rates at Blackpool Victoria Hospital, a high-prevalence area, one year before and one year after the publication of the new guidelines. In the year after publication the rate of HIV testing in patients with indicator diseases was as follows: hepatitis B $6 \%$, hepatitis C $28 \%$, tuberculosis $9 \%$ and lymphoma $14 \%$. The overall rate of HIV testing in acute medical admissions was $0.5 \%$. Our results demonstrate that traditional methods of guideline dissemination did not lead to implementation. We are now assessing alternative methods such as marking all positive laboratory results for indicator diseases with the phrase 'HIV testing should be considered' and implementing universal opt-out screening in our Clinical Decisions Unit.
\end{abstract}

Correspondence to I Page, Department of Infectious Diseases, North Manchester General Hospital, Delaunays Road Manchester M8 5RB, UK tel. +44 (0)7974805378 e-mail lainpage9@hotmail.com

KEYWORDS HIV, hepatitis, lymphoma, testing, tuberculosis

DECLARATION OF INTERESTS A poster of this research was presented the Tenth International Congress on Drug Therapy in HIV Infection in Glasgow.

\section{INTRODUCTION}

In September 2008 the British HIV Association (BHIVA) issued revised guidelines for the testing of patients for human immunodeficiency virus (HIV) in the UK.' The key points of the advice were:

- HIV is now a treatable medical condition and the majority of those living with the virus remain fit and well on treatment.

- Despite this, a significant number of people in the UK are unaware of their HIV infection and remain at risk to their own health and of unwittingly passing their virus on to others.

- Late diagnosis is the most important factor associated with HIV-related morbidity and mortality in the UK.

- Patients should therefore be offered, and encouraged to accept, HIV testing in a wider range of settings than is currently the case.

- Patients with specific indicator conditions should be routinely recommended to have an HIV test.

- All doctors, nurses and midwives should be able to obtain informed consent for an HIV test in the same way that they currently do for any other medical investigation (our emphasis).

Two key aspects of the new guidelines are that patients diagnosed with 'clinical indicator conditions' (Table I, overleaf) should be offered a test as part of routine clinical practice by the clinician responsible for their care

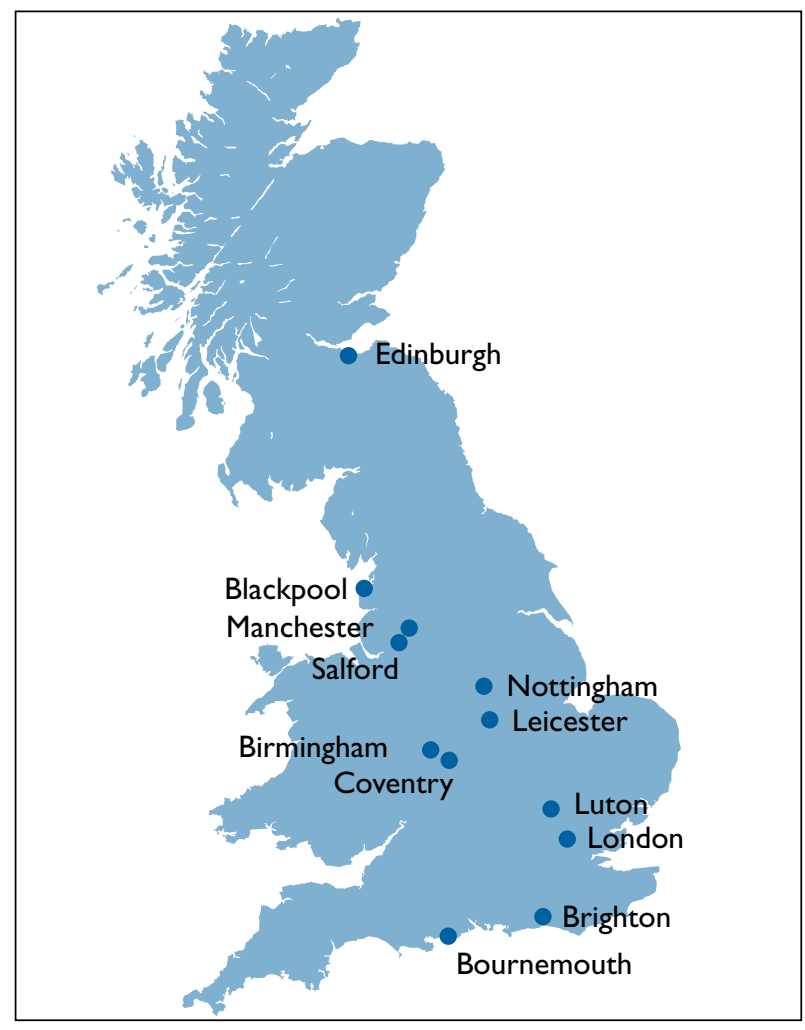

FIGURE I Map of UK towns with high HIV seroprevalence.

at that time. Patients with these conditions should be offered HIV testing regardless of the presence or absence of other risk factors. These diseases include 
TABLE I Conditions where HIV testing is indicated'

\begin{tabular}{|c|c|c|}
\hline Specialty & AIDS-defining conditions & Other conditions where HIV testing should be offered \\
\hline Respiratory & $\begin{array}{l}\text { Tuberculosis } \\
\text { Pneumocystis pneumonia }\end{array}$ & $\begin{array}{l}\text { Bacterial pneumonia } \\
\text { Aspergillosis }\end{array}$ \\
\hline Neurology & $\begin{array}{l}\text { Cerebral toxoplasmosis } \\
\text { Primary cerebral lymphoma } \\
\text { Cryptococcal meningitis } \\
\text { Progressive multifocal leucoencephalopathy }\end{array}$ & $\begin{array}{l}\text { Aseptic meningitis } \\
\text { Cerebral abscess } \\
\text { Space-occupying lesion of unknown cause } \\
\text { Guillain-Barré syndrome } \\
\text { Transverse myelitis } \\
\text { Peripheral neuropathy } \\
\text { Dementia } \\
\text { Leucoencephalopathy }\end{array}$ \\
\hline Dermatology & Kaposi's sarcoma & $\begin{array}{l}\text { Severe seborrhoeic dermatitis } \\
\text { Severe psoriasis } \\
\text { Multi-dermatomal or recurrent shingles }\end{array}$ \\
\hline Gastroenterology & Persistent cryptosporidiosis & $\begin{array}{l}\text { Oral candidiasis } \\
\text { Oral hairy leukoplakia } \\
\text { Chronic diarrhoea of unknown cause } \\
\text { Weight loss of unknown cause } \\
\text { Salmonella, Shigella or Campylobacter } \\
\text { Hepatitis B } \\
\text { Hepatitis C }\end{array}$ \\
\hline Oncology & Non-Hodgkin’s lymphoma & $\begin{array}{l}\text { Anal cancer or intraepithelial dysplasia } \\
\text { Lung cancer } \\
\text { Seminoma } \\
\text { Head and neck cancer } \\
\text { Hodgkin's disease } \\
\text { Castleman's disease }\end{array}$ \\
\hline Gynaecology & Cervical cancer & $\begin{array}{l}\text { Cervical intraepithelial neoplasia Grade } 2 \text { or above } \\
\text { Vaginal intraepithelial neoplasia }\end{array}$ \\
\hline Haematology & & Any unexplained blood dyscrasia \\
\hline Ophthalmology & Cytomegalovirus retinitis & $\begin{array}{l}\text { Any unexplained retinopathy } \\
\text { Herpes simplex virus or toxoplasma retinitis }\end{array}$ \\
\hline Ear, nose, throat & & Chronic parotitis \\
\hline Others & & $\begin{array}{l}\text { Mononucleosis-like syndrome } \\
\text { Pyrexia of unknown origin } \\
\text { Lymphadenopathy of unknown cause } \\
\text { Any sexually transmitted infection }\end{array}$ \\
\hline
\end{tabular}

several common conditions likely to be encountered by all physicians, such as bacterial pneumonia, dementia and peripheral neuropathy.

The new guidelines also state that, in areas of high HIV seroprevalence (Figure I), testing should also be routinely offered and performed in all general medical admissions (as has been standard practice in the US for several years) and in all adults registering at a general practitioner's.

High prevalence is defined by the BHIVA as greater than two in I,000. In England the Health Protection Agency (HPA) has published these data for each primary care trust (PCT). Each city with at least one PCT meeting this criterion is marked on the map. London has several PCTs that meet this gauge, but others that do not. A full list of PCTs with a high prevalence can be found on the HPA website. ${ }^{2}$ In Scotland data have been compiled for each health board by Health Protection Scotland. Only Lothian has a high prevalence and is marked on the map by its main city, Edinburgh. No areas of Wales or Northern Ireland have a high prevalence.

Blackpool is located in an area of high seroprevalence for HIV infection (3.59 per thousand population). Blackpool Victoria Hospital is the district general hospital providing care for the region and has the advantage of a specialist HIV team. Inpatient care is led by an infectious diseases consultant and outpatient care has the additional input of the genito-urinary medicine (GUM) department. Only patients with known HIV are under the care of the specialist team, which has no direct control over HIV testing outside of its own clinical services. This remains at the discretion of the physician responsible for each individual patient's care within the hospital trust. 
The HIV team responded to the new guidelines with efforts to disseminate them throughout the trust. No new resources were available to facilitate guideline compliance. The guidelines were, however, emailed to all relevant clinicians in the hospital together with an explanatory covering letter summarising the recommendations. A hospital grand round was held on the topic as part of the regular postgraduate educational programme. The session lasted for an hour and involved presentation of the guidelines, followed by an open-floor discussion. It was well attended by physicians working in the hospital and the new guidelines were well received with no specific objections being raised to their implementation. We thus expected to see an increase in HIV testing following guideline dissemination and set out to measure the impact of these measures one year after the guidelines were introduced.

\section{METHODS}

One year after the publication of the guidelines we calculated our rates of testing in acute general medical admissions and for patients diagnosed with key indicator diseases - tuberculosis, hepatitis B or C and lymphoma for the period of one year before and after publication. These conditions were selected as they were common and had clearly defined diagnostic criteria. Testing for each of these conditions was performed on site. We used the laboratory database to create lists of those diagnosed with these conditions and manually cross-referenced against all the named HIV tests taken within the same time period.

Patients were included if they met the following criteria: positive culture for tuberculosis (acid-fast bacilli seen on microscopy or mycobacterium tuberculosis grown on culture), positive serology for hepatitis B or C and positive histology for lymphoma. All HIV tests performed by clinicians at this hospital were included. Those tested in GUM clinic were excluded from both the clinical indicator condition diagnosis lists and the HIV testing lists. We felt this was appropriate as we were aiming to assess whether non-specialist clinicians were providing HIV testing in accordance with guidelines.

We also compared the total number of tests requested from medical wards for one year before and after guideline publication to the total number of acute admissions to the medical wards in that time - data that were routinely compiled by hospital management.

The work related to this paper was aimed solely at improving implementation of accepted guidelines and did not involve any experimental alteration to any patient's care. As a result, ethical approval was not sought. As the data generated for this report were based on searches of existing laboratory data and no identifiable patient data have been published we did not generate any patient consent forms.
TABLE 2 Testing in patients with indicator conditions

\begin{tabular}{|l|l|l|l|l|}
\hline \multirow{2}{*}{} & \multicolumn{2}{|l|}{$\begin{array}{l}\text { One year before } \\
\text { guidelines (Oct } \\
\text { 2007-Sept 2008) }\end{array}$} & \multicolumn{2}{l|}{$\begin{array}{l}\text { One year after } \\
\text { guidelines (Oct } \\
\text { 2008-Sept 2009) }\end{array}$} \\
\cline { 2 - 5 } & $\begin{array}{l}\text { Patients } \\
\text { with } \\
\text { indicator } \\
\text { condition } \\
(\mathrm{n})\end{array}$ & $\begin{array}{l}\text { Of these } \\
\text { tested } \\
\text { for HIV } \\
(\mathrm{n})\end{array}$ & $\begin{array}{l}\text { Patients } \\
\text { with } \\
\text { indicator } \\
\text { condition } \\
\text { (n) }\end{array}$ & $\begin{array}{l}\text { Of these } \\
\text { tested } \\
\text { for HIV } \\
(\mathrm{n})\end{array}$ \\
\hline Hepatitis B & 40 & $4(10 \%)$ & 32 & $2(6 \%)$ \\
\hline Hepatitis C & 131 & $6 \mathrm{I}(47 \%)$ & 88 & $25(28 \%)$ \\
\hline Tuberculosis & 33 & $\mathrm{I}(3 \%)$ & $\mathrm{II}$ & $\mathrm{I}(9 \%)$ \\
\hline Lymphoma & 28 & $0(0 \%)$ & 25 & $4(16 \%)$ \\
\hline
\end{tabular}

TABLE 3 Overall testing rates for general medical admissions

\begin{tabular}{|l|l|l|}
\hline & $\begin{array}{l}\text { Oct 2007- } \\
\text { Sept 2008 }\end{array}$ & $\begin{array}{l}\text { Oct 2008- } \\
\text { Sept 2009 }\end{array}$ \\
\hline General medical admissions (n) & 12,052 & 13,999 \\
\hline $\begin{array}{l}\text { HIV tests requested from } \\
\text { medical wards }(\mathrm{n})\end{array}$ & $36(0.3 \%)$ & $72(0.5 \%)$ \\
\hline
\end{tabular}

\section{RESULTS}

Between I October 2007 and 30 September 2009, there were 388 triggering diagnostic episodes in total (219 hepatitis C, 72 hepatitis B, 44 tuberculosis, 53 lymphoma). A total of 98 patients ( $26 \%$ of total) had a named HIV test. Of these patients, hepatitis $C$ diagnosis was most likely to trigger an HIV test (39.3\% patients had tests) and tuberculosis diagnoses the least likely (4\%). Guideline dissemination seems to have had no effect on our chosen indicator illnesses with the exception of lymphoma, where testing rates improved from zero to $16 \%$.

Overall, however, there were fewer named patient tests in the one year period after 30 September 2008 (32 of $156[20 \%]$ ) than the year before it (66 of 232 patients [28\%]). The number of HIV tests performed on patients in acute medical admissions rose from 36 pre-guideline to 72 post-guideline, but this represented a tiny fraction of the potentially testable patients admitted. The results are summarised in Tables 2 and 3. While the increase in the testing rate in the clinical decision unit was statistically significant $(p<0.00 \mathrm{I})$, we do not regard the attainment of a $0.5 \%$ testing rate as clinically significant, given that the guidelines suggest testing should be offered to $100 \%$ of patients in this environment.

\section{DISCUSSION}

It is clear that our traditional strategy of guideline dissemination via grand rounds and e-mails to consultants did not result in the desired change in practice, as there was no clinically significant increase in testing. With respect to viral hepatitis, rates of HIV testing actually fell in the year after the guidelines were published and disseminated. 
It seems apparent that most non-HIV clinicians in this high-prevalence area are still not screening for HIV, even when clinical indicator diseases are present.

We find it hard to explain this seeming reluctance to test for a relatively common disease which can be diagnosed by a simple blood test and has an effective treatment resulting in near-normal life expectancy but which, left untreated, results in death within a few years. Our concern is that HIV is still seen as a 'special' disease that can only be tested for by specialist doctors following extensive pre-test counselling. These attitudes may have been appropriate in the days when HIV was incurable, but are no longer appropriate. Current guidelines make it clear that HIV should now be treated in the same way as any other condition, with pre-test counselling and consent taken in the same way as for any other test.

Given the high seroprevalence of HIV in our area, it seems likely that undiagnosed HIV-infected patients have passed through our system without being tested, thus leaving them at risk of severe AIDS-related illness and death. We would therefore suggest that doctors should be willing to perform an HIV test without hesitation when an indicator disease is present - or, indeed, if patients are in a high-risk group such as intravenous drug abusers - as there are few other conditions where choosing to perform a simple blood test can have such massive prognostic implications.

Our attempt to alter attitudes and achieve 'normalisation' of HIV testing through our grand round presentation and e-mail dissemination to relevant clinicians has not been effective in altering clinical practice. We are therefore now assessing the feasibility of more aggressive strategies to bring about an increase in testing. This will involve dissemination of the results of this audit to all clinicians and its presentation at departmental audit meetings, as well as a redistribution of the national guideline recommendations in a simplified format.

Since several major clinical indicator diseases such as hepatitis, tuberculosis and lymphoma are diagnosed by the local laboratory service, we are also considering marking all positive results with advice that 'HIV testing is recommended' in the hope this will encourage higher

\section{REFERENCES}

I British HIV Association. UK national guidelines for HIV testing. London: BHIVA; 2008. Available from: http://www.bhiva.org/ documents/Guidelines/Testing/GlinesHIVTest08.pdf

2 http://www.hpa.org.uk/Topics/InfectiousDiseases/InfectionsAZ/HIV/ OverallHIVPrevalence

3 Medical Foundation for AIDS \& Sexual Health. Recommended standards for NHS HIV services. London: MedFASH; 2003. Available from: http://www.medfash.org.uk/publications/documents/ Recommended_standards_for_NHS_HIV_services.pdf

4 Heijman RL, Stolte IG,Thiesbrummel HF et al. Opting out increases HIV testing in a large sexually transmitted infections rates of testing by the clinician responsible for the patient's care. This strategy could be adopted by most hospital laboratories at minimal cost.

At a governance level, however, we believe that testing strategies for HIV require greater support and resource provision from trust management. As we are in a highprevalence area we are considering the practicalities of implementing universal opt-out testing for all acute medical admissions. This might initially seem to be both prohibitively complex and an expensive indulgence in an era of financial austerity. However, we note that the BHIVA definition of high seroprevalence is the result of cost-effectiveness calculations. The cost of testing is therefore expected to be offset by other savings. There is an expectation that early HIV diagnoses will reduce the number and duration of complex (and thus expensive) admissions often needed to treat advanced illness or AIDS. It will also reduce the likelihood of onward transmission of HIV infection with vast savings for each transmission prevented. ${ }^{3}$

We therefore advocate the introduction of universal HIV testing in all general medical admissions in areas of high HIV seroprevalence. We expect this will both improve clinical outcomes and reduce overall cost of HIV care in these areas. We note that universal opt-out testing for HIV has been operating for some years in both the ante-natal clinics and sexual health clinics throughout the UK and Europe. Rates of HIV test acceptance in these settings have been high. ${ }^{45}$ Pilot studies of universal opt-out testing have been performed in medical admissions units with good rates of HIV test uptake. ${ }^{6}$ They have also shown that HIV testing in these environments is acceptable to patients.

Above all, we would emphasise the benefits to patients of diagnosing HIV early in its natural course. We hope that the description of our experience will raise awareness of the new guidelines and encourage all clinicians in all parts of the UK to perform HIV testing as routine when patients are diagnosed with clinical indicator diseases.

Acknowledgments Thanks to Dr John Sweeney and Dr Wafaa Wasef, GUM Consultants at Blackpool Victoria Hospital, for their assistance in planning this project. Thanks to Health Protection Scotland for providing data on HIV prevalence in Scotland and HPA for confirming the rates for Wales and Northern Ireland.

outpatient clinic. Sex Transm Infect 2009; 85:249-55. doi:I0.II36/ sti.2008.033258

5 Podhurst LS, Storm DS, Dolgonos S. Women's opinions about routine HIV testing during pregnancy: implications for the opt-out approach. AIDS Patient Care STDS 2009; 23:331-7. doi:I0.1089/ apc.2008.0186

6 Perry N, Heald L, Cassell J et al. HIV testing in acute general admissions must be universally offered to reduce undiagnosed HIV infection. HIV Med 20 I0; I I (Suppl. I):9. Available from: http:// www.bhiva.org/documents/Conferences/Manchester2010/ Abstracts I0Entire.pdf 